\title{
GEOPHYSICAL PROPERTIES OF SOILS
}

\author{
J. Carlos Santamarina and Junghee Park \\ Earth Science \& Engineering, King Abdullah University of Science and Technology (KAUST)
}

\begin{abstract}
Low energy perturbations used in geophysical methods provide insightful information about constant-fabric soil properties and their spatial variability. There are causal links between soil type, index properties, elastic wave velocity, electromagnetic wave parameters and thermal properties. Soil type relates to the stress-dependent S-wave velocity, thermal and electrical conductivity and permittivity. The small strain stiffness reflects the state of stress, the extent of diagenetic cementation and/or freezing. Pore fluid chemistry, fluid phase and changes in either fluid chemistry or phase manifest through electromagnetic measurements. The volumetric water content measured with electromagnetic techniques is the best predictor of porosity if the water saturation is $100 \%$. Changes in water saturation alter the P-wave velocity when $S_{r} \rightarrow 100 \%$, the S-wave velocity at intermediate saturations, and the thermal conductivity when the saturation is low $S_{r} \rightarrow 0 \%$. Finally, tabulated values suffice to estimate heat capacity and latent heat for engineering design, however thermal conductivity requires measurements under proper field conditions.
\end{abstract}

\section{$1 \quad$ INTRODUCTION}

Geophysical methods have played a crucial role in subsurface characterization, in the detection of hydrocarbon and mineral resources, and in monitoring a wide range of subsurface processes. Geophysical surveys are minimally invasive and involve low-energy stimuli, thus, they are inherently non-destructive constant-fabric measurements. In addition, the same geophysical assessment takes place in laboratory studies as in field surveys (Note: laboratory measurements may require careful analysis prior to the interpretation of field data due to frequency-dependent wave dispersion and scattering).

Geophysical parameters are most relevant to engineering design. This manuscript presents a concise yet practical summary of the geophysical properties of soils. The four central themes include: soil classification, characterization with elastic waves, characterization with electromagnetic waves and thermal properties.

\section{SOIL CLASSIFICATION}

The purpose of soil classification is to anticipate the behaviour of soils by grouping them into similar response categories based on simple index properties. This section summarizes a revised soil classification system RSCS that builds on the accumulated field experience since the introduction of the Unified Soil Classification System USCS in the 1930’s.

Step 1: Coarse or fine? Let's accept the general definition of gravel (retained on sieve \#4), sand (passing through sieve \#4 and retained on sieve \#200) and fines (passing through sieve \#200). Any one of these soil components can control the mechanical and hydraulic behaviour of a soil mixture. For example, a densely packed sand near $e_{S}^{\text {min }}$ will carry the load and control the mechanical behaviour of a sand-gravel mixture when the gravel is looser than $e_{G}^{\max }$. Similar analyses define the 13 notable mixtures listed in Table 1 . The gravimetric-volume equations presented in this table compute the corresponding fractions for gravel, sand and fines. Specific factors included in the definition of these mixtures reflect an extensive database of soil properties (details in Park \& Santamarina 2016). These notable mixtures determine classification boundaries in the triangular RSCS classification chart. Analyses and experimental data demonstrate that mixture thresholds are different for flow and mechanical control. Table 1 presents the classification procedure:

- Input the coefficient of uniformity $C_{u}$ and the mean particle roundness $R$, of gravel and sand fractions (or their values of $e^{\max }$ and $e^{\min }$ ).

- Input the liquid limit $L L$ of fines (or the void ratio of fines at $\sigma=10 \mathrm{kPa}, \sigma=1 \mathrm{MPa}$, and at the liquid limit $L L$ ).

- Compute notable mixtures (1)-through-9) for mechanical-control and (10)-through-13) for flow control; plot the 13 notable mixtures on the triangular chart and draw the classification boundaries. Note: the Excel file available on the authors' websites simultaneously draws the chart, classification boundaries and plots the point that represents the soil under consideration.

- Classify the soil under consideration. The double letter nomenclature recognizes: first, the soil fraction that controls the mechanical behaviour and second, the soil fraction that controls flow (in parenthesis). 
Table 1: Revised Soil Classification System RSCS.

Background:
Physics-based: gravimetric-volumetric analysis
Data-driven: takes into consideration extensive databases of soil behaviour
Input:
$\begin{array}{llll}\text { Gravel } G(>4.75 \mathrm{~mm}) & F_{G} & e_{G}^{\max } \text { and } e_{G}^{\min } & \text { or roundness } R \text { and uniformity } C_{u} \\ \text { Sand } S(0.075 \sim 4.75 \mathrm{~mm}) & F_{S} & e_{S}^{\max } \text { and } e_{S}^{\min } & \text { or roundness } R \text { and uniformity } C_{u} \\ \text { Fines } F(<0.075 \mathrm{~mm}) & F_{F} & \left.e_{F}\right|^{10 \mathrm{kPa}},\left.e_{F}\right|^{1 \mathrm{MPa}}, \text { and }\left.e_{F}\right|^{\mathrm{LL}} & \text { or liquid limit } L L\end{array}$

\section{Compute Threshold Fractions}

Gravel fraction $\mathrm{F}_{\mathrm{G}}=\mathrm{M}_{\mathrm{G}} / \mathrm{M}_{\mathrm{T}}$

Sand fraction $\mathrm{F}_{\mathrm{S}}=\mathrm{M}_{\mathrm{S}} / \mathrm{M}_{\mathrm{T}}$

$F_{G}=\left(1+\frac{e_{G}}{1+e_{S}}+\frac{e_{S}}{1+e_{F}} \frac{e_{G}}{1+e_{S}}\right)^{-1} \quad F_{S}=\left(\frac{1+e_{S}}{e_{G}}+1+\frac{e_{S}}{1+e_{F}}\right)^{-1}$
Fines fraction $\mathrm{F}_{\mathrm{F}}=\mathrm{M}_{\mathrm{F}} / \mathrm{M}_{\mathrm{T}}$

$F_{F}=\left(\frac{1+e_{S}}{e_{G}} \frac{1+e_{F}}{e_{S}}+\frac{1+e_{F}}{e_{S}}+1\right)^{-1}$

\section{Support information \& Correlations:}

Fines: Fluid flow $\left.\quad e_{F}\right|^{\text {flow }}=0.05 L L \log (L L-25)$

Fines: Load carrying $\left.e_{F}\right|^{10 k P a}=\left.e_{F}\right|^{1 k P a}-C_{c}=0.026 L L+0.07$

$$
\begin{aligned}
& \left.e_{F}\right|^{1 M P a}=\left.e_{F}\right|^{1 k P a}-3 C_{c}=0.011 L L+0.21 \\
& e_{C}^{\min }=-0.012+\frac{0.082}{R}+\frac{0.371}{C_{u}}
\end{aligned}
$$

Gravel and sand:

$$
e_{C}^{\max }=0.032+\frac{0.154}{R}+\frac{0.522}{C_{u}}
$$

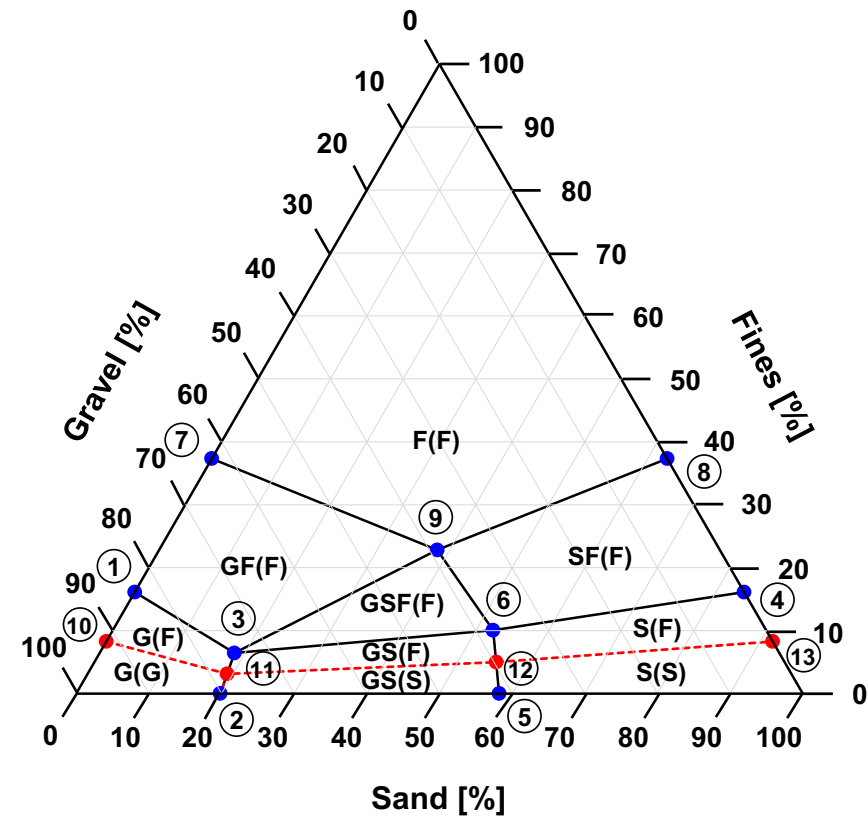

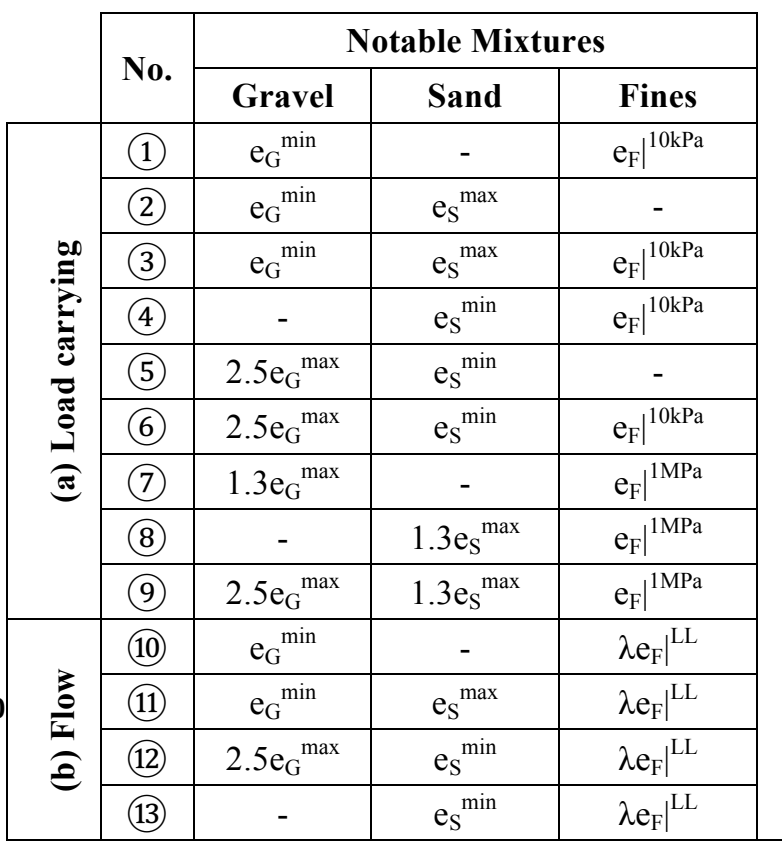

Classify the soil. Report the two-name nomenclature: first letter/letters indicate the load-carrying fraction the second letter indicates the flow-controlling fraction. If either letter is $F \rightarrow$ proceed to classify the fines - Table 2.

Sources: Park and Santamarina (2016).

Step 2: Fines classification. Soils that are fines-controlled -either in their mechanical and/or flow response- require further analysis to determine that type of fines. The most salient characteristics of fines are (1) their specific surface, assessed by the liquid limit, and (2) their sensitivity to pore fluid chemistry. We determine fluid sensitivity by running liquid limits with deionized water $L L_{\mathrm{DW}}$, brine $L L_{\text {brine }}$ to collapse the double layer ( $2 \mathrm{M} \mathrm{NaCl} \mathrm{solution}$ ), and kerosene $L L_{\mathrm{ker}}$ to explore the effect of van der Waals forces. Measured liquid limits are corrected for specific gravity and precipitated salts. Then two ratios $L L_{\mathrm{ker}} / L L_{\text {brine }}$ and $L L_{\mathrm{DW}} / L L_{\text {brine }}$ combine the corrected values as demonstrated in Table 2. The electrical sensitivity $S_{E}$ captures the distance between measured values and the absolute "non-sensitive" soil response at $L L_{\mathrm{ker}} / L L_{\mathrm{brine}}=1$ and $L L_{\mathrm{DW}} / L L_{\mathrm{brine}}=1$. The two-letter pair classification of a fine soil recognizes its plasticity and its electrical sensitivity (Table 2). 
Table 2: Fines Classification based on Plasticity and Sensitivity to Pore-Fluid Chemistry.
Background:
Specific surface and sensitivity to pore fluid chemistry are the salient characteristics of fines.
Input: Three liquid limits (soil fraction passes sieve \#200 - fall cone method BSI 1990)
Sediment mixed with deionized water $L L_{D W}$, kerosene $L L_{\text {ker }}$, and 2-M NaCl brine $L L_{\text {brine }}$.
Compute corrected liquid limit ratios
$\left.\frac{L L_{\mathrm{ker}}}{L L_{\text {brine }}}\right|_{\text {corr }}=\frac{L L_{\mathrm{ker}}}{L L_{\text {brine }}} \frac{1-c_{\text {brine }} \frac{L L_{\text {brine }}}{100}}{G_{\mathrm{ker}}}$ and $\left.\frac{L L_{D W}}{L L_{\text {brine }}}\right|_{\text {corr }}=\frac{L L_{D W}}{L L_{\text {brine }}}\left(1-c_{\text {brine }} \frac{L L_{\text {brine }}}{100}\right)$
where $G_{k e r}$ is the specific gravity of kerosene; $c_{\text {brine }}=$ concentration of $\mathrm{NaCl}$ brine [mol/L]
Calculate the electrical sensitivity $S_{E}$ (use ratios above, or their inverse such that they are $\geq 1$ )
$S_{E}^{\text {left }}=\sqrt{\left(\frac{L L_{\mathrm{ker}}}{L L_{\text {brine }}}-1\right)^{2}+\left(\frac{L L_{D W}}{L L_{\text {brine }}}-1\right)^{2}} \quad$ or $\quad S_{E}^{(\text {right })}=\sqrt{\left(\frac{L L_{\text {brine }}}{L L_{\mathrm{ker}}}-1\right)^{2}+\left(\frac{L L_{D W}}{L L_{\text {brine }}}-1\right)^{2}}$
Classify the soil
Report the two-letter pair for
- Plasticity
- Electrical sensitivity

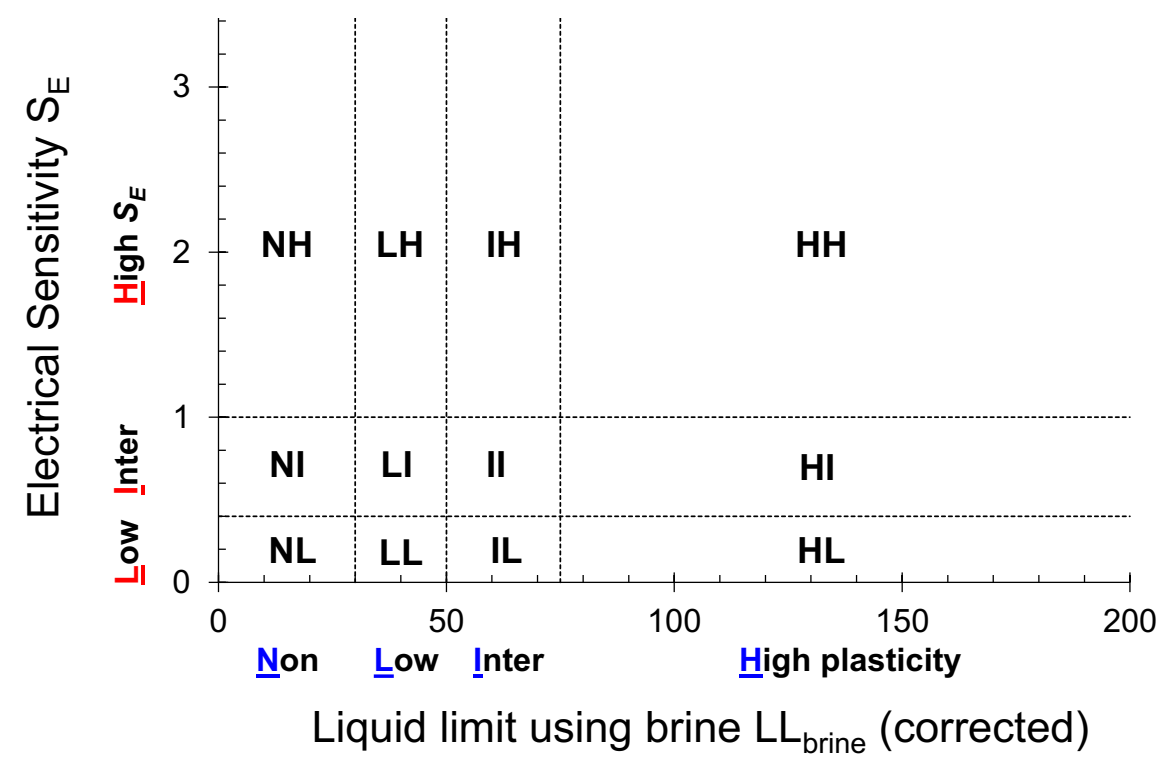

Sources: Jang and Santamarina (2016a); Jang and Santamarina (2016b)

\section{ELASTIC WAVES}

A small-strain mechanical perturbation propagates through the soil mass as an elastic wave. The wave equation for mechanical wave propagation combines Newton's law $\mathrm{F}=\mathrm{m} \cdot \mathrm{a}=\mathrm{m} \cdot \mathrm{d}^{2} \mathrm{u} / \mathrm{dt}^{2}$, dynamic force equilibrium, constitutive equations (Hooke's law $\sigma=\mathrm{E} \varepsilon$ ), and compatibility of deformations. The resulting wave equation anticipates two modes of propagation in a linear-elastic, homogeneous, isotropic, single-phase and infinite continuum: (1) S-waves where the particle motion is normal to the direction of propagation, and (2) P-waves where the particle motion is in the direction of wave propagation. New forms of wave propagation emerge anytime the above assumptions are relaxed, for example: shock waves (large strain); reflection, refraction and scatter (heterogeneous); S-wave splitting (anisotropy); slow \& fast waves (mixed phase); Rayleigh, Love, and tube waves (bounded media). 
Wave velocity. The shear stiffness of the granular skeleton $G_{s k}$ defines the S-wave velocity $V_{S}$. Therefore, $V_{S}$ increases with effective stress, diagenesis (e.g., cementation, creep, and salt precipitation), and suction (Table 3).

The P-wave velocity $V_{P}$ depends on the constrained modulus of the soil $M_{\text {soil }}$, which is a function of the shear stiffness of the skeleton $G_{s k}$ (see above) and the bulk stiffness of the soil $B_{\text {soil }}$. The bulk stiffness of the soil can be computed by successive substitutions to capture (Table 3): the skeleton stiffness $B_{s k}$ and porosity $n$, the stiffness of water and air $B_{w}$ and $B_{a}$, and the degree of saturation $S_{r}$ as presented in Table 3.

$\underline{V}_{P} / \underline{V}_{s}$ - Poisson's ratio. Theory of elasticity anticipates that the ratio $V_{P} / V_{S}$ is a function of Poisson's ratio $v$ (Table 3 ). For small-strain wave propagation, Poisson's ratio is $v=0.15 \pm 0.05$ for dry or unsaturated soils, but it tends to $v \rightarrow 0.5$ for well saturated soils; for example, Poisson's ratio can be $v=0.485$ for a saturated sand $20 \mathrm{~m}$ deep and exceed $v=0.499$ for a saturated soft clay.

Table 3: Elastic Waves: Velocity.

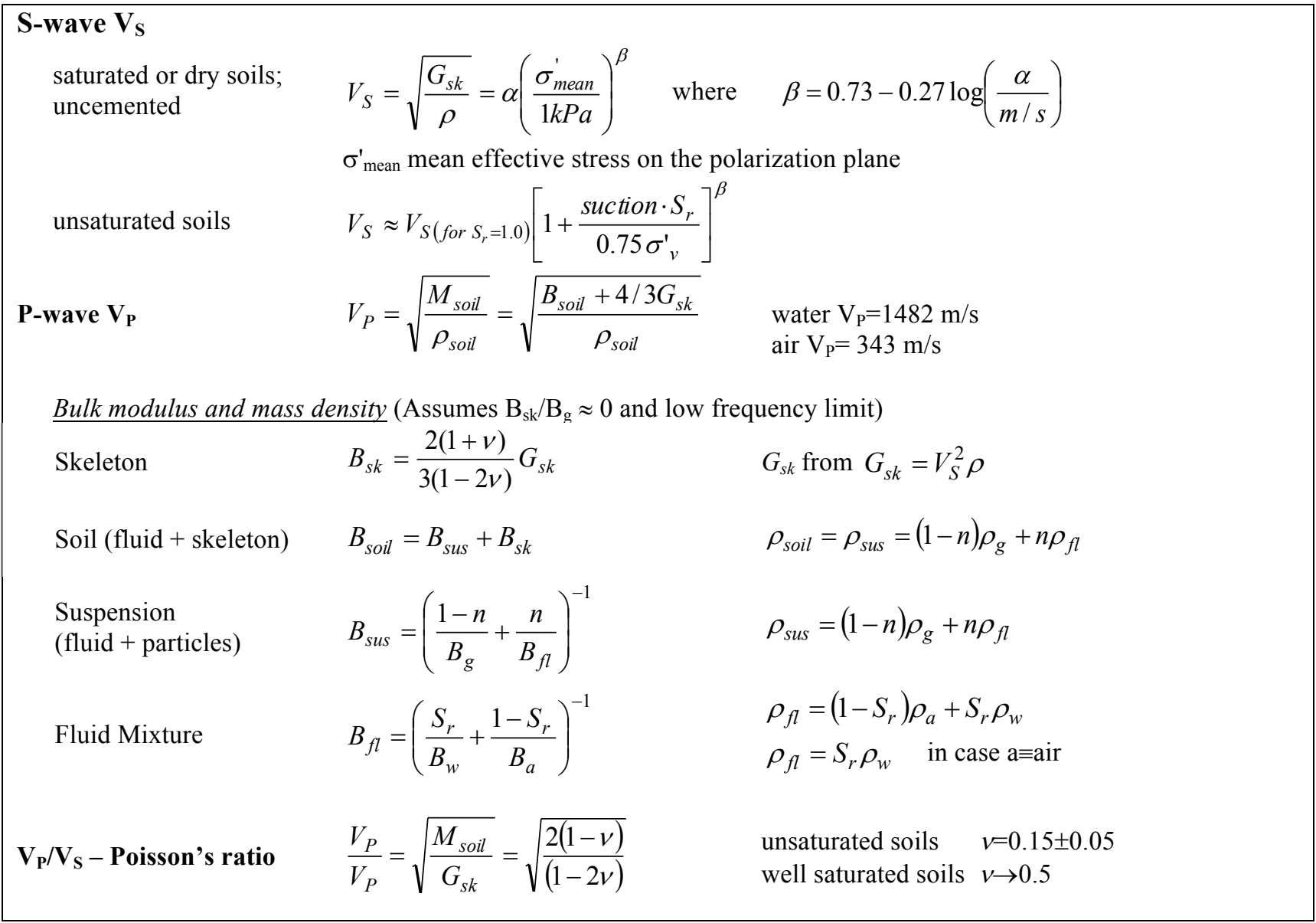

Sources: Richart et al. (1970); Hardin and Drnevich (1972); Reynolds (1997); Santamarina et al. (2001); Cho and Santamarina (2001). Based on an earlier compendium by Santamarina et al. 2005.

Attenuation. The wave amplitude decreases with distance due to (Table 4): geometric spreading of the propagating spherical or cylindrical front (i.e., same energy across a larger area), reflection and backscatter at interfaces (lower transmitted energy), and unrecovered energy consumed while deforming the material as the wave propagates (viscous, thermoelastic and/or frictional losses). Geometric spreading vanishes in plane waves. 
Table 4: Elastic Waves: Attenuation.

Attenuation $\frac{A_{2}}{A_{1}}=\left(\frac{r_{1}}{r_{2}}\right)^{\varsigma} T e^{-\alpha\left(r_{2}-r_{1}\right)}$

Ratio between the amplitude of particle motion $A$ at radial distances $r_{1}$ and $r_{2}$ [m]

Transmission coefficient $T$ across an interface: a function of relative impedance

Exponent: plane wave $\varsigma=0$; cylindrical front $\varsigma=0.5$; spherical front $\varsigma=1$

Relationship between linear attenuation coefficient $\alpha[1 / \mathrm{m}]$, skin depth $S d[\mathrm{~m}]$, and damping ratio $D$ :

$$
\alpha=\frac{1}{S_{d}}=\frac{2 \pi D}{\lambda} \quad \text { Note: the skin depth in terms of wavelengths is } \frac{S_{d}}{\lambda}=\frac{1}{2 \pi D}
$$

\section{Physical processes in material attenuation}

Dry - small strain:

thermo-elastic relaxation

Moist/wet - small strain:

viscous loss prevails

Large strain:

frictional loss

Typical damping values at small strain for $P$ - and $S$ - waves

\begin{tabular}{|c|c|c|c|}
\hline \multicolumn{2}{|l|}{ Material } & $\underline{\text { Damping } D}$ & Comments \\
\hline \multicolumn{2}{|l|}{ Air } & $2 \times 10^{-4}$ & Changes with relative humidity \\
\hline \multicolumn{2}{|l|}{ Water } & $2 \times 10^{-6}$ & Increases with dissolved gas \\
\hline \multirow[t]{2}{*}{ Coarse soils } & $d r y$ & $0.002 \sim 0.008$ & Increases when wet \\
\hline & saturated & $0.005 \sim 0.02$ & \\
\hline Fine soils & saturated & $0.01 \sim 0.05$ & \\
\hline Organic soils & saturated & $0.01 \sim 0.05$ & \\
\hline \multirow[t]{2}{*}{ Rocks } & $d r y$ & $0.002 \sim 0.004$ & \\
\hline & wet & $0.006 \sim 0.025$ & \\
\hline
\end{tabular}

Notes: $\gamma$ is the strain, $\sigma_{0}{ }^{\prime}$ is the effective confinement, $\mathrm{w}_{\mathrm{g}}$ is the gravimetric water content.

Sources: Johnston and Toksoz 1980; Yasuda and Matsumoto (1993); Kim et al. (1991); Laird and Stokoe (1993); Santamarina and Cascante (1996); Li et al. (1998); Kokusho (1980); Kokusho et al. (1982); Cascante and Santamarina (1996); Diaz-Rodriguez and Santamarina (2001); Kim and Novak (1981).

\section{ELECTROMAGNETIC WAVES}

An electrical or magnetic transient propagates through the soil mass as an electromagnetic wave. The wave equation for electromagnetic waves results from Maxwell's equations. The electrical field and the magnetic field oscillate transversely to the direction of propagation and to each other.

There are three electromagnetic material parameters: magnetic permeability $\mu$, electrical conductivity $\sigma_{e l}$, permittivity $\kappa$. Permittivity and permeability are complex quantities because they represent both in-and-out of phase responses. The three material parameters combine to determine the propagation velocity $V$ and the material attenuation coefficient $\alpha$ or skin depth $S_{d}=1 / \alpha$ i.e., is the distance travelled by a plane wave when its amplitude decreases to $1 / e$ of the initial amplitude. Table 5 summarizes equations for wave velocity and skin depth. Typically, most fluids and solids in the subsurface are either paramagnetic or diamagnetic; then, velocity and skin depth equations become those listed in the second half of Table 5.

Magnetization and polarization losses add to Ohmic conduction to render an effective conductivity. When the effective conductivity is high, the first term of the wave equation prevails and the electromagnetic transient propagates in diffusional mode. 
Table 5: Electromagnetic Waves: Velocity and Attenuation.

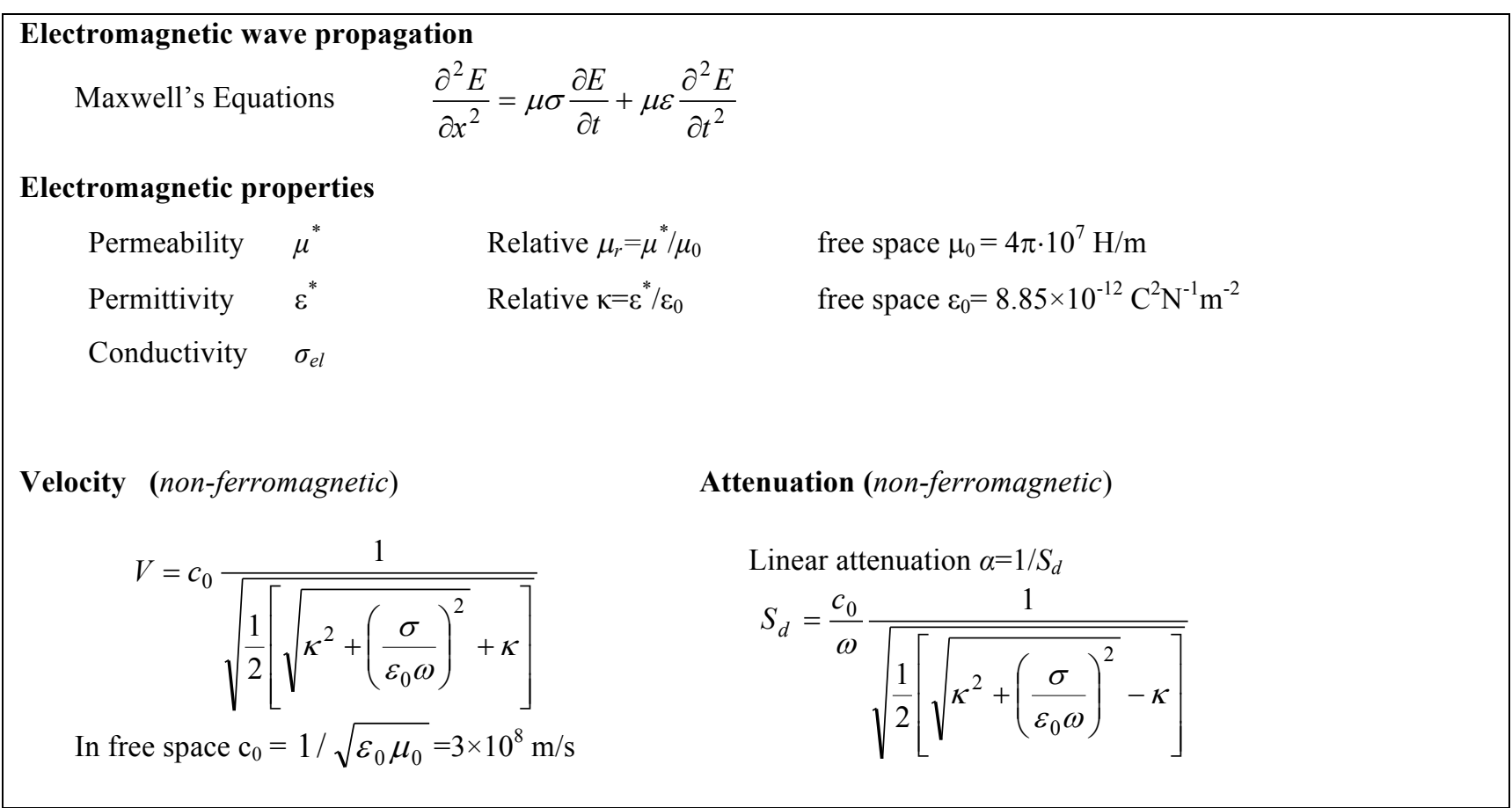

Electrical conductivity. The movement of hydrated ions is responsible for electrical conduction in geomaterials. Hydrated ions imply the presence of water, dissolved salts (both cations and anions), and hydrated counter-ions next to charged mineral surfaces (diffuse double layer). Therefore, the electrical conductivity of soils is proportional to the volumetric water content, the conductivity of the pore fluid which increases linearly with salt concentration $c$ (for low $c<\sim 0.2 \mathrm{M})$, and the specific surface of the soil; Table 6 lists convenient semi-empirical models. Pore fluid conductivity prevails in sands and silts, while surface conduction gains relevance in low porosity, high specific surface clayey sediments saturated with low salt concentration water (Table 6).

Permittivity. Permittivity is a measure of polarizability. Free water molecules control the permittivity of soils and rocks in the MHz-to-GHz frequency range; therefore, the permittivity of wet soils is proportional to the volumetric water content $\theta_{v}=S_{r} n$. By contrast, the orientational polarization of water is hindered when water is frozen, in adsorbed layers close to mineral surfaces and when water molecules hydrate ions. Table 7 summarizes semi-empirical models.

Permeability. We can assume that soils are non-ferromagnetic in the absence of ferromagnetic inclusions. Otherwise, the volume fraction of ferromagnetic inclusions determines the magnetic permeability of the soil (Table 8). 
Table 6: Electrical Conductivity.

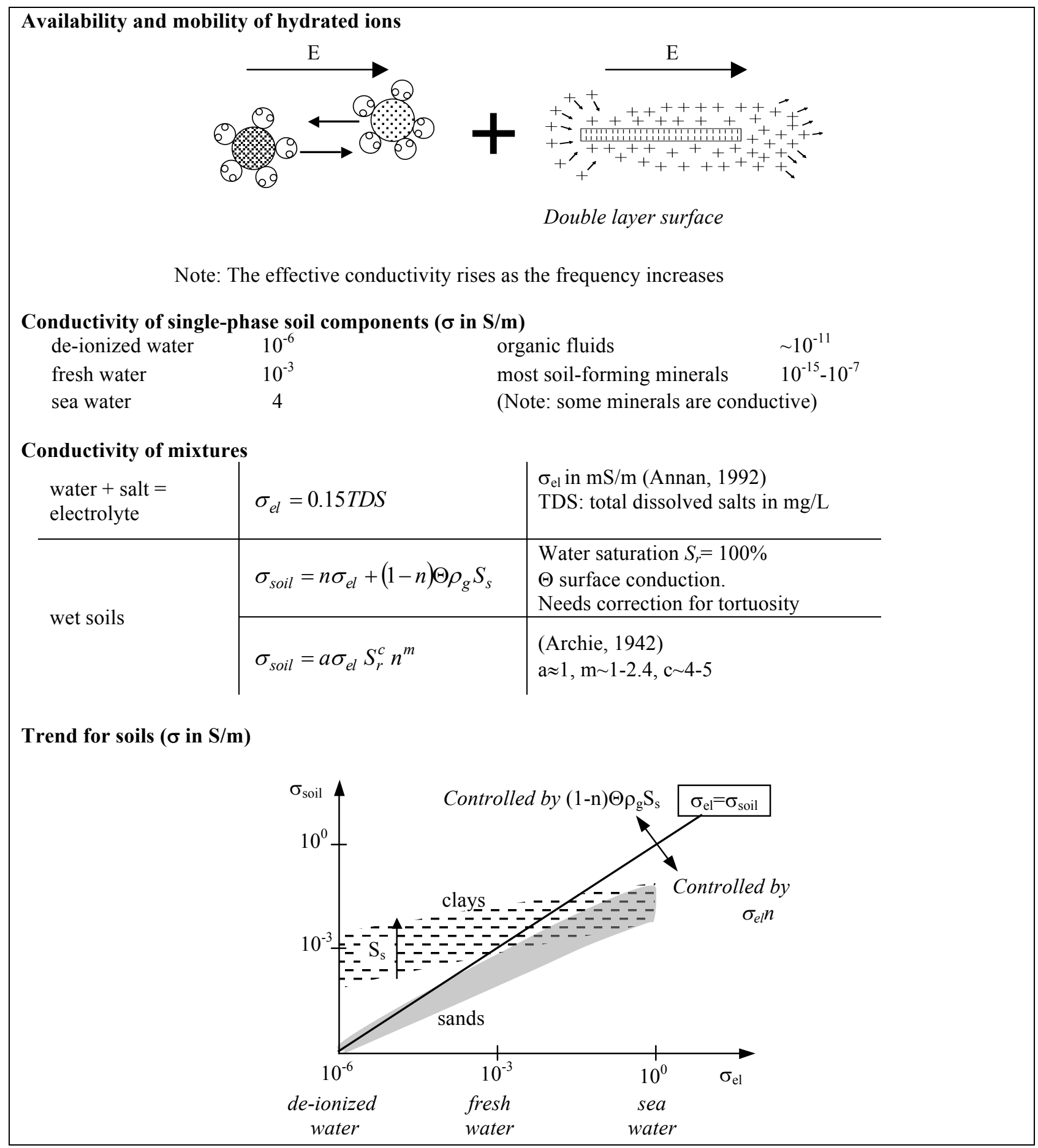

Notes: The surface conduction for kaolinite is about $\Theta \approx 10^{-9}$ Siemens. Tortuosity may reduce the electrical conductivity in clays more than in sands. Hence, the conductivity of marine clays may be lower than the conductivity of marine sands, at the same void ratio.

Sources: Annan (1992); Reynolds (1997); Santamarina et al. (2001). Based on an earlier compendium by Santamarina et al. (2005). 
Table 7: Permittivity (Relevant frequency range $1 \mathrm{MHz}-1 \mathrm{GHz}$ ).

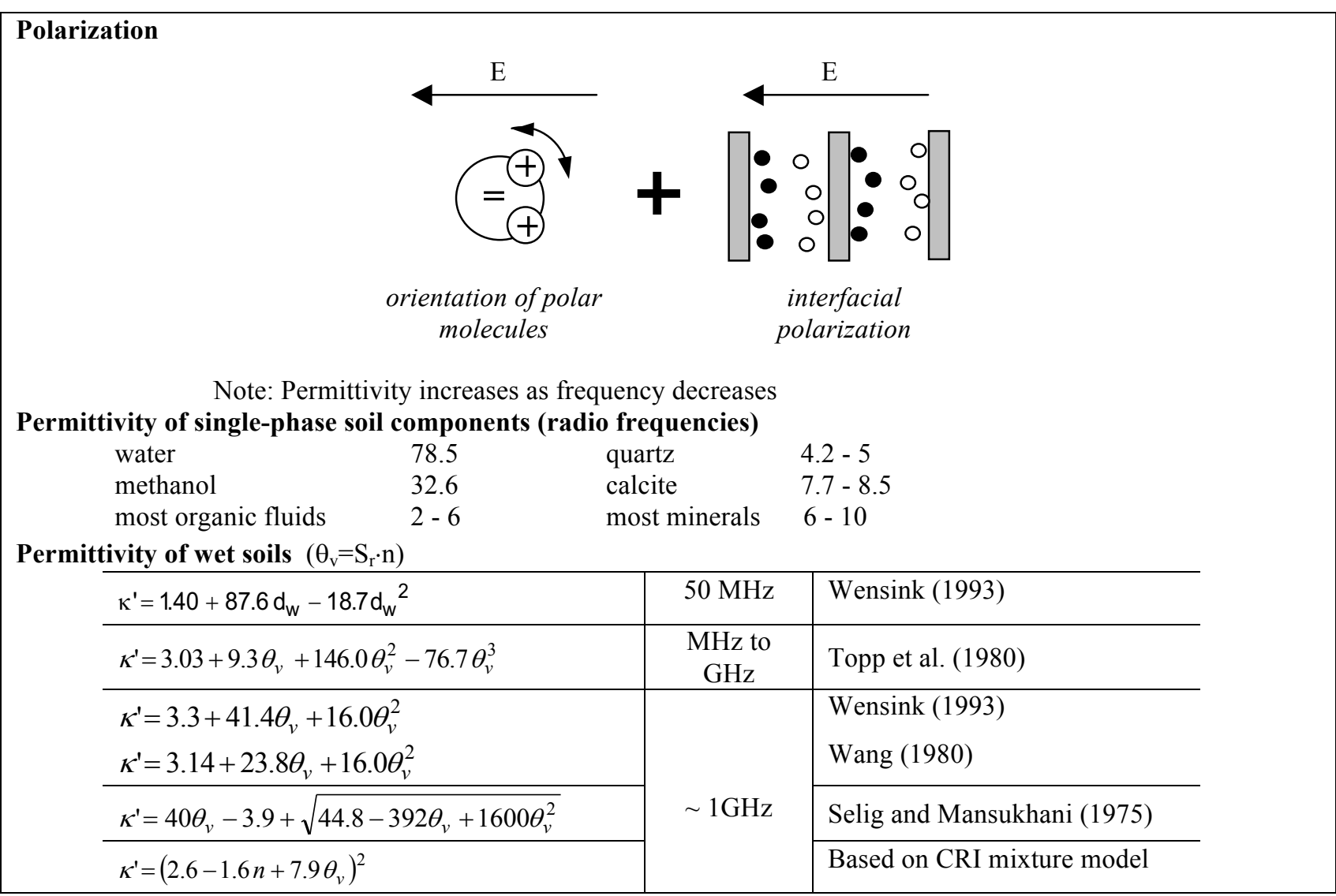

Table 8: Magnetic Permeability.

Magnetization
Single materials
water, quartz, kaolinite
montmorillonite, illite, granite, hematite
nickel, iron
Predictive relations
Wagner's model for spherical particles
Kaolinite with iron filings (at $10 \mathrm{kHz})$
$(2)$

Sources: (1) Göktürk et al. (1993); (2) Klein and Santamarina (2000)

Note: $\mathrm{v}_{\mathrm{Fe}}$ is the volume fraction of ferromagnetic inclusions 


\section{THERMAL PROPERTIES}

A change in temperature propagates as a diffusion front through the soil mass, facilitated by the thermal conductivity of the soil yet hindered by the heat consumed in changing the temperature of the soil mass. The propagating thermal front causes volume strains, and phase changes may take place (vapour $\leftrightarrow$ liquid $\leftrightarrow$ solid). Consequently, the thermal properties of soils include: thermal diffusivity $D_{T}$, thermal conductivity $k_{T}$, specific heat $c_{p}$, latent heat $L$, and volumetric thermal expansion coefficient $\alpha_{T}$. Table 9 presents definitions and typical values.

Table 9: Thermal Phenomena in Soils.

\begin{tabular}{|c|c|c|c|c|c|c|}
\hline \multicolumn{7}{|c|}{$\begin{array}{l}\text { Latent heat } L[\mathrm{~kJ} / \mathrm{kg}]: \text { Heat required for phase transformation at constant temperature. } \\
\text { Specific heat } c_{p}\left[\mathrm{Jkg}^{-1} \mathrm{~K}^{-1}\right]: \text { Heat required to increase the temperature of } 1 \mathrm{~kg} \text { by } 1 \mathrm{~K} . \\
\text { Thermal conductivity } k_{T}\left[\mathrm{Wm}^{-1} \mathrm{~K}^{-1}\right] \text { : relates the heat flux density } \mathrm{q}\left[\mathrm{J} / \mathrm{sec} / \mathrm{m}^{2}\right] \text { to the thermal gradient } \\
\mathrm{q}=\underline{k}_{T} \Delta \mathrm{T} / \Delta \mathrm{x} \text { (Fourier's heat law) } \\
\text { Thermal diffusivity: } \mathrm{D}_{\mathrm{T}}=\mathrm{k}_{\mathrm{T}} / \rho c_{p} \text {. } \\
\text { Volumetric expansion coeff } \alpha_{\mathrm{T}}\left[\mathrm{K}^{-1}\right] \text { : Relates temperature change to strain } \varepsilon=\alpha \Delta \mathrm{T}\end{array}$} \\
\hline \multicolumn{7}{|c|}{ Typical values } \\
\hline & Material & $\begin{array}{c}\text { Latent } \\
\text { heat } \\
{[\mathrm{kJ} / \mathrm{kg}]}\end{array}$ & $\begin{array}{c}\text { Specific } \\
\text { heat } c_{p} \\
{\left[\mathrm{Jkg}^{-1} \mathrm{~K}^{-1}\right]}\end{array}$ & $\begin{array}{l}\text { Thermal } \\
\text { conduct. } k_{T} \\
{\left[\mathrm{Wm}^{-1} \mathrm{~K}^{-1}\right]}\end{array}$ & $\begin{array}{c}\text { Thermal } \\
\text { diffusivity } D_{T} \\
{\left[\mathrm{~m}^{2} \sec ^{-1} \times 10^{-7}\right]}\end{array}$ & $\begin{array}{c}\text { Volumetric thermal } \\
\text { expansion coefficient } \\
\alpha_{\mathrm{T}}\left[10^{-6} \mathrm{~K}^{-1}\right]\end{array}$ \\
\hline \multicolumn{2}{|c|}{ Quartz (single crystal) } & & 750 & $12(\|)-6.8(\perp)$ & 45 & $800(\|)-1400(\perp)$ \\
\hline \multicolumn{2}{|l|}{ Shale } & & 630 & 1.56 & 31 & \\
\hline \multicolumn{2}{|c|}{ Limestone } & & 900 & 1.3 & 27 & 3.3 \\
\hline \multirow{2}{*}{ Sand } & dry & & 800 & $0.15-0.33$ & & \\
\hline & water sat & & 2200 & $2-4$ & & \\
\hline \multicolumn{2}{|l|}{ Water } & 334 & 4200 & 0.6 & 1.4 & 200 (at $293 \mathrm{~K}$ ) \\
\hline \multicolumn{2}{|c|}{ Ice $\left(0^{\circ} \mathrm{C}\right)$} & 334 & 2040 & 2.2 & 11.2 & 51 (at $273 \mathrm{~K})$ \\
\hline \multicolumn{2}{|l|}{ Air } & & 1000 & 0.024 & 0.21 & 3400 (at $293 \mathrm{~K}$ ) \\
\hline
\end{tabular}

Trends: General $k_{T}{ }^{\text {dry soil }}<k_{T}{ }^{\text {wet soil }}<k_{T}$ mineral

$$
\begin{array}{lll}
\text { Dry soils } & k_{T, \text { dry }}=\frac{0.135 \rho_{d r y}+64.7}{\rho_{g}-0.947 \rho_{d r y}} \\
\text { Wet soils } & k_{T, \text { wet }}=k_{T, \text { dry }}+\left(1-e^{-0.89 S_{r}}\right)\left(k_{T, \text { sat }}-k_{T, \text { dry }}\right) \quad \text { (Ewen and Thomas 1987) }
\end{array}
$$

Thermal conduction: Grain and pore-scale processes

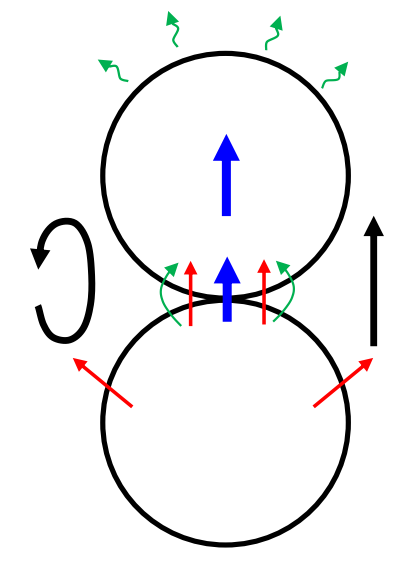

Particle conduction

Contact conduction

Radiation

Particle-particle radiation

Particle-fluid conduction

Particle-fluid-part conduction

Pore fluid conduction

Pore fluid convection
$\underline{\boldsymbol{k}}_{\underline{T}}$ increase with:

- porosity $n \downarrow$

- effective stress $\sigma^{\prime} \uparrow$ (heat transfer at contacts $\uparrow$ )

- water content $\uparrow$

- quartz content $\uparrow$

- frozen water

- coarser grains

In general, we can use tabulated values and gravimetric or volumetric averages to estimate thermal properties for engineering analyses, except for the thermal conductivity (and hence diffusivity). Thermal conduction depends on:

- The type of mineral: quartz exhibits particularly high thermal conductivity

- The coordination number between grains: denser soils exhibit higher $k_{T}$

- The quality of contacts: contact resistance decreases as stress increases (it follows a power function that resembles Hertzian contact behaviour), and in cemented soils 
- The presence of water: while the thermal conductivity of water is lower than that of most minerals, the presence of water at contacts has a pronounced effect on the thermal conduction across contacts and the conductivity of the soil.

Table 9 schematically summarizes thermal conduction phenomena.

\section{CLOSING THOUGHTS: GEOPHYSICS AND ENGINEERING}

The previous sections identify various causal links between geophysical properties, soil type, index properties and soil behaviour. Salient causal relations follow:

- Soil type: related to stress-dependent changes in the S-wave velocity, thermal conductivity, electrical conductivity and permittivity.

- Small strain shear stiffness (for deformation-based design): it is computed from $\mathrm{S}$-wave velocity $\mathrm{V}_{\mathrm{s}}$ measurements using cross-hole downhole and surface wave methods. Shear stiffness and $\mathrm{V}_{\mathrm{s}}$ reflect effective stress -including suction, extent of diagenetic cementation and/or freezing. Exercise caution when soils are unsaturated as variation in saturation levels will result in changes in the shear stiffness.

- Porosity: from the volumetric water content calculated with electromagnetic measurements using ground penetrating radar, electrical resistivity or time domain reflectometry. In addition, electromagnetic parameters can be used to detect time-varying water saturation, pore fluid chemistry, and fluid phase (e.g., freezing).

- Other geophysical parameters mirror time varying water saturation, including P-wave velocity when $S_{r} \rightarrow 100 \%$, S-wave velocity for intermediate saturations, and thermal conductivity when $S_{r} \rightarrow 0 \%$.

- Thermal properties are needed for the design of systems such as buried cable installations and thermal piles. Specific and latent heats are gravimetric or volumetric averages of tabulated values for the individual soil components. The thermal conductivity (and hence diffusivity) can be measured in the lab under proper field stress and moisture conditions.

\section{ACKNOWLEDGEMENTS}

This research is supported by the KAUST endowment. G. Abelskamp edited the manuscript. The authors are grateful to the organizers of the 5th International Conference on Geotechnical and Geophysical Site Characterization.

\section{$8 \quad$ LIST OF SYMBOLS}

$\alpha \quad$ attenuation coefficient

$\alpha_{\mathrm{T}} \quad$ volumetric thermal expansion coefficient

$\alpha, \beta \quad$ fitting parameters in velocity-stress relation

$\Delta \quad$ energy loss/cycle

$\varepsilon \quad$ strain

$\varepsilon^{*} \quad$ complex permittivity

$\varepsilon_{0} \quad$ permittivity of free space, $\varepsilon_{0}=8.85 \times 10^{-12} \mathrm{C}^{2} /\left(\mathrm{N} \cdot \mathrm{m}^{2}\right)=8.85 \times 10^{-12} \mathrm{~F} / \mathrm{m}$

$\gamma \quad$ shear strain $\left(\gamma_{\text {elas }}\right.$ elastic threshold strain)

$\kappa \quad$ relative permittivity

$\lambda \quad$ wavelength

$\mu^{*} \quad$ magnetic permeability (subscript $\mathrm{r}$ : relative permeability)

$\mu_{0} \quad$ magnetic permeability of free space, $\mu_{0}=4 \pi \times 10^{7} \mathrm{H} / \mathrm{m}$

$v \quad$ Poisson's ratio

$\theta_{\mathrm{v}} \quad$ volumetric water content

$\Theta \quad$ surface conduction

$\rho \quad$ mass density (fl: fluid; g: mineral that makes the grains; sus: suspension; dry: bulk dry)

$\varsigma \quad$ exponent in geometric attenuation that depends on wave front

$\sigma_{\mathrm{el}} \quad$ electrical conductivity (el: electrolyte; fl: fluid)

$\sigma \quad$ stress ( $\sigma^{\prime}$ : effective stress; v: vertical; h: horizontal; mean: mean in polarization plane)

$\omega \quad$ angular frequency

A amplitude

a, c, $m$ constants used in Archie's equation

B bulk stiffness (sk: soil skeleton; g: mineral that makes grains; sus: suspension; fl: fluid) 


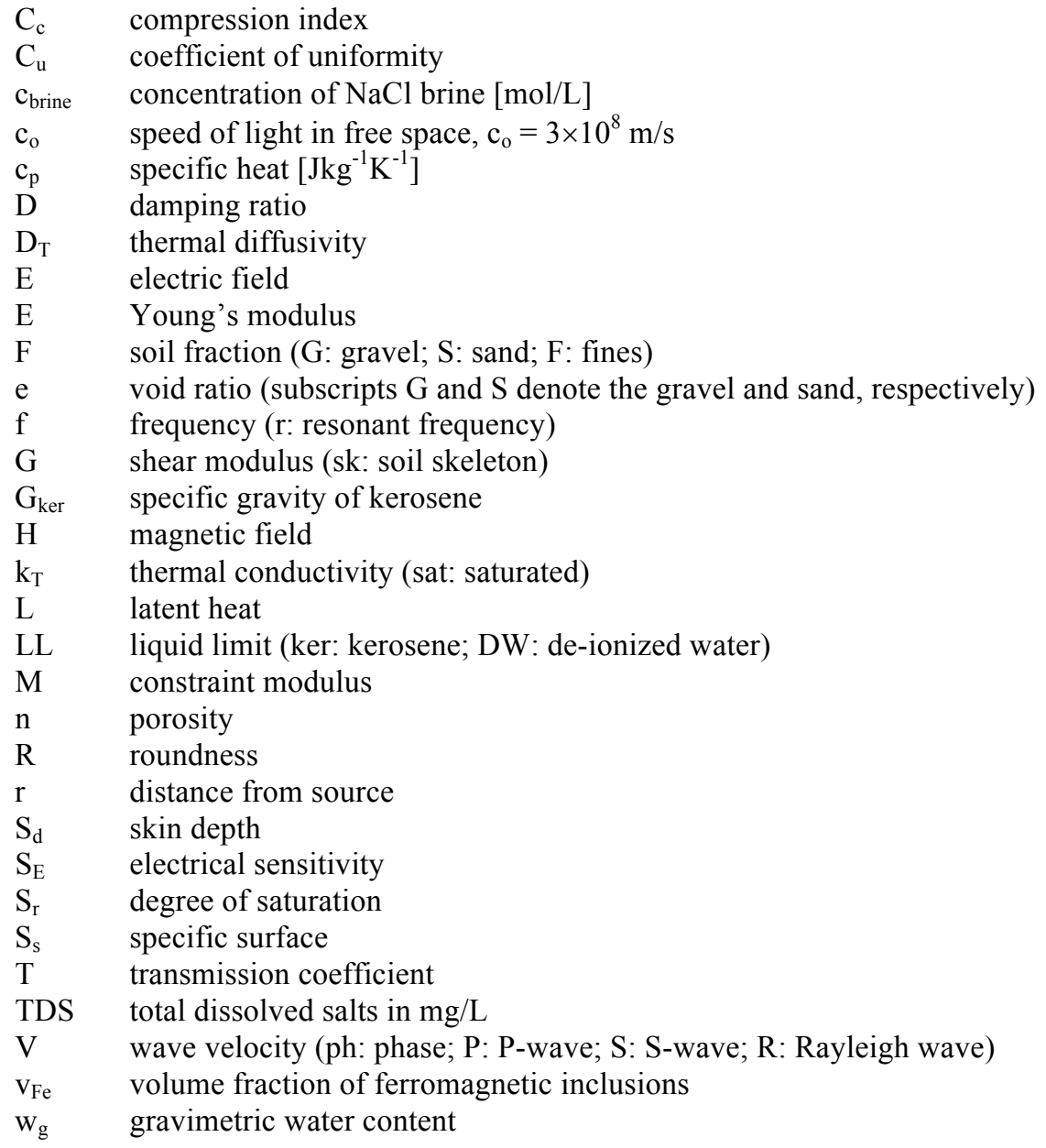

\section{REFERENCES}

Annan, A. P. (1992). Ground penetrating radar, Workshop Notes, Sensors and Software, Mississauga.

Archie, G. E. (1942). The electrical resistivity log as an aid in determining some reservoir characteristics: Transactions of the American Institute of Mining, Metallurgical and Petroleum Engineers, 146, 54-62.

Cascante, G. and Santamarina, J. C. (1996). Interparticle contact behavior and wave propagation. Journal of Geotechnical Engineering, ASCE, 122(10), 831-839.

Cho, G. C. and Santamarina, J. C. (2001). Unsaturated particulate materials - particle level studies. Journal of Geotechnical Geoenvironmental Engineering, ASCE, 127, 84-96.

Dìaz-Rodrìguez, J.A. and Santamarina, J.C. (2001), Mexico city soil behavior at different strains: observations and physical interpretation. Journal of Geotechnical and Geoenvironmental Engineering, ASCE, 127, 783-789.

Ewen, J., and Thomas, H. R. (1987). The thermal probe - a new method and its use on an unsaturated sand. Geotechnique, 37(1), 91-105.

Göktürk, H. S., Fiske, T. J. and Kalyon, D. M. (1993). Electric and magnetic properties of a thermoplastic elastomer incorporated with ferromagnetic powders. IEEE Transactions on Magnetics, 29, 4170-4176.

Hardin, B. O. and Drnevich, V. P. (1972). Shear modulus and damping in soils: measurement and parameter effects. Journal of Soil Mechanics Foundation Division, ASCE, 98, 603-624.

Jang, J. and Santamarina, J. C. (2016a). Fines classification based on sensitivity to pore-fluid chemistry. Journal of Geotechnical and Geoenvironmental Engineering, ASCE, 142 (4), p.06015018.

Jang, J. and Santamarina, J. C. (2016b). Closure of "Fines classification based on sensitivity to pore-fluid chemistry". Journal of Geotechnical and Geoenvironmental Engineering, ASCE (in progress).

Johansen, T. A. (1975). Thermal conductivity of soils. US Army Corps of Engineers, Trondheim, Hanover, New Hampshire.

Johnston, D.H. and Toksöz, M.N. (1980). Ultrasonic P and S wave attenuation in dry and saturated rocks under pressure. Journal of Geophysical Research: Solid Earth, 85(B2), 925-936.

Kim, T.C. and Novak, M. (1981). Dynamic properties of some cohesive soils of Ontario. Canadian Geotechnical Journal, 18, 371-389. 
Kim, D. S., Stokoe, K. H. and Hudson, W. R. (1991). Deformational characteristics of soils at small to intermediate strains from cyclic tests. Report 1177-3, Center for Transportation Research, Bureau of Engineering Research, the University of Texas Austin, 142 pages.

Klein, K. and J. C. Santamarina. (2000). Ferromagnetic inclusions in geomaterials - implications. Geotechnical Journal, ASCE, 162, 167-179.

Kokusho, T. (1980). Cyclic triaxial test of dynamic soil properties for wide strain range. Soils and Foundations, 20, $45-$ 60.

Kokusho, T., Yoshida, Y. and Esashi, Y. (1982). Dynamic properties of soft clay for wide strain range. Soils and Foundations, 22, 1-18.

Laird, J. P. and Stokoe, K. H. (1993). Dynamic properties of remolded and undisturbed soil samples tested at high confining pressures. Geotechnical Engineering Report GR93-6, Electrical Power Research Institute, Palo Alto, Calif.

Li, X. S., Yang, W. L., Shen, C. K., and Wang, W. C. (1998). Energy-injecting virtual mass resonant column system. Journal of Geotechnical and Geoenvironmental Engineering, ASCE, 124, 428-438.

O'Konski, C. T. (1960). Electrical properties of macromolecules V. Theory of ionic polarization in polyelectrolytes. Journal of Physical Chemistry, 64, 605-618.

Park, J and Santamarina, J. C. (2016). Revised soil classification system for coarse-fine mixtures. Journal of Geotechnical and Geoenvironmental Engineering, ASCE (Under review).

Reynolds, J.M. (1997). An introduction to applied and environmental geophysics. John Wiley and Sons, Chichester, U.K., 796 pages.

Richart, F. E., Hall, J. R., and Woods, R. D. (1970). Vibrations of soils and foundations, Prentice Hall, Englewood Cliffs, 414 pages.

Santamarina, J. C. and Cascante, G. (1996). Stress anisotropy and wave propagation: a micromechanical view. Canadian Geotechnical Journal, 33, 770-782.

Santamarina, J. C., Klein, K. A., and Fam, M. A. (2001). Soils and waves. John Wiley \& Sons, LTD. New York, 488 pages.

Selig, E. T. and Mansukhani, S. (1975). Relationship of soil moisture to the dielectric property. Journal of the Geotechnical Engineering Division, 101, 757-770.

Topp, G. C., Davis, J. L., Bailey, W. G. and Zebchuk, W. D. (1980). The measurement of soil water content using a portable TDR hand probe. Canadian Journal of Soil Science, 64, 313-321.

Wang, J. R. (1980). The dielectric properties of soil-water mixtures at microwave frequencies. Radio Science, 15, $977-$ 985.

Wensink, W. A. (1993). Dielectric properties of wet soils in the frequency range 1-3000 MHz. Geophysical Prospecting, 41, 671-696.

Yasuda, N. and Matsumoto, N. (1993). Dynamic deformation characteristics of sand and rockfill materials. Canadian Geotechnical Journal, 30, 747-757. 